\title{
FIXED POINTS OF HAMMERSTEIN-TYPE EQUATIONS ON GENERAL CONES
}

\author{
RUBÉN FIGUEROA* AND F. ADRIÁN F. TOJO** \\ * Departamento de Análise Matemática, Facultade de Matemáticas \\ Universidade de Santiago de Compostela, Spain \\ E-mail: ruben.figueroa@usc.es \\ ***Departamento de Análise Matemática, Facultade de Matemáticas \\ Universidade de Santiago de Compostela, Spain \\ E-mail: fernandoadrian.fernandez@usc.es
}

\begin{abstract}
We obtain new results on the existence and multiplicity of fixed points of Hammerstein equations in very general cones. In order to achieve this, we combine a new formulation of cones in terms of continuous functionals with fixed point index theory. Many examples and an application to boundary value problems are also included.
\end{abstract}

Key Words and Phrases: Cones, fixed points, Hammerstein equations.

2010 Mathematics Subject Classification: 37C25, 47H30, 34B15.

\section{REFERENCES}

[1] M.A. Alghamdi, D. O'Regan, N. Shahzad, Krasnosel'skǐ type fixed point theorems for mappings on nonconvex sets, Abstr. Appl. Anal., 2012(2012).

[2] H. Amann, Fixed point equations and nonlinear eigenvalue problems in ordered banach spaces, SIAM Rev., 18(1976), no. 4, 620-709.

[3] V. Anuradha, D. Hai, R. Shivaji, Existence results for superlinear semipositone bvp's, Proc. Amer. Math. Soc., 124(1996), no. 3, 757-763.

[4] R. Avery, A. Peterson, Three positive fixed points of nonlinear operators on ordered banach spaces, Computers \& Mathematics with Applications, 42(2001), no. 3, 313-322.

[5] M. Berzig, S. Chandok, M.S. Khan, Generalized krasnosel'skiน fixed point theorem involving auxiliary functions in bimetric spaces and application to two-point boundary value problem, Appl. Math. Comput., 248(2014), 323-327.

[6] A. Cabada, J. Á. Cid, G. Infante, New criteria for the existence of non-trivial fixed points in cones, Fixed Point Theory and Applications, 2013(2013), no. 1, 1-12.

[7] A. Cabada, J. Á. Cid, G. Infante, A positive fixed point theorem with applications to systems of hammerstein integral equations, Boundary Value Problems, 2014(2014), no. 1, 1-10.

[8] G. Cai, S. Bu, Krasnoselskii-type fixed point theorems with applications to hammerstein integral equations in $l 1$ spaces, Mathematische Nachrichten, 286(2013), no. 14-15, 1452-1465.

Supported by FPU Scholarship, Ministerio de Educación, Cultura y Deporte (Spain). Partially supported by Ministerio de Economía y Competitividad (Spain) project MTM2013-43014-P and Xunta de Galicia (Spain), project EM2014/032. 
[9] C. Chidume, Y. Shehu, Approximation of solutions of equations of hammerstein type in Hilbert spaces, Fixed Point Theory, 16(2015), no. 1, 91-101.

[10] J. Cid, G. Infante, M. Tvrdỳ, M. Zima, A topological approach to periodic oscillations related to the liebau phenomenon, J. Math. Anal. Appl., 423(2015), no. 2, 1546-1556.

[11] B. Dhage, S. Ntouyas, A krasnosel'skiน nonlinear alternative type fixed point theorem with applications to nonlinear integral equations, Indian J. Maths., 56(2014), no. 1, 113-124.

[12] Y. Dongming, Z. Qiang, P. Zhigang, Existence of positive solutions for neumann boundary value problem with a variable coefficient, Int. J. Differ. Equ., 2011(2011).

[13] W.F. Donoghue, Distributions and Fourier transforms, Academic Press, 1969.

[14] L. Erbe, Eigenvalue criteria for existence of positive solutions to nonlinear boundary value problems, Mathematical and Computer Modelling, 32(2000), no. 5, 529-539.

[15] D. Franco, G. Infante, J. Perán, A new criterion for the existence of multiple solutions in cones, Proceedings of the Royal Society of Edinburgh, Section A Mathematics, 142(2012), no. 5, 1043-1050.

[16] C.S. Goodrich, On nonlocal bvps with nonlinear boundary conditions with asymptotically sublinear or superlinear growth, Math. Nachr., 285(2012), no. 11-12, 1404-1421.

[17] C.S. Goodrich, Positive solutions to boundary value problems with nonlinear boundary conditions, Nonlinear Anal., 75(2012), no. 1, 417-432.

[18] C.S. Goodrich, On a nonlocal bvp with nonlinear boundary conditions, Results in Mathematics, 63(2013), no. 3-4, 1351-1364.

[19] C.S. Goodrich, On nonlinear boundary conditions satisfying certain asymptotic behavior, Nonlinear Anal., 76(2013), 58-67.

[20] D. Guo, V. Lakshmikantham, Nonlinear problems in abstract cones, Academic Press, 2014.

[21] G. Infante, P. Pietramala, Nonlocal impulsive boundary value problems with solutions that change sign, Mathematical Models in Engineering, Biology and Medicine. Conference on Boundary Value Problems. September 16-19, 2008, Santiago de Compostela, Spain, 22.

[22] G. Infante, P. Pietramala, Perturbed Hammerstein integral inclusions with solutions that change sign, Comment. Math. Univ. Carolin., 50(2009), no. 4, 591-605.

[23] G. Infante, P. Pietramala, The displacement of a sliding bar subject to nonlinear controllers, Differential and Difference Equations with Applications, Springer, 2013, 429-437.

[24] G. Infante, P. Pietramala, M. Tenuta, Existence and localization of positive solutions for a nonlocal bvp arising in chemical reactor theory, Commun. Nonlinear Sci. Numer. Simul., 19(2014), no. 7, 2245-2251.

[25] G. Infante, P. Pietramala, F.A.F. Tojo, Nontrivial solutions of local and nonlocal neumann boundary value problems, Proc. Edinb. Math. Sect. A., (to appear).

[26] G. Infante, P. Pietramala, M. Zima, Positive solutions for a class of nonlocal impulsive bvps via fixed point index, Topological Methods in Nonlinear Anal., 36(2010), no. 2, 263-284.

[27] G. Infante, J. Webb, Three point boundary value problems with solutions that change sign, J. Integral Equations Appl., 15(2003), 37-57.

[28] G. Infante, J. Webb, Nonlinear non-local boundary-value problems and perturbed hammerstein integral equations, Proc. Edinb. Math. Soc. (2), 49(2006), no. 3, 637-656.

[29] T. Jankowski, Nonnegative solutions to nonlocal boundary value problems for systems of secondorder differential equations dependent on the first-order derivatives, Nonlinear Anal., 87(2013), 83-101.

[30] J. Jiang, L. Liu, Y. Wu, Positive solutions for second-order singular semipositone differential equations involving Stieltjes integral conditions, Abstract and Applied Analysis, Volume 2012, Special Issue (2012), Article ID 696283, 21 pages.

[31] M. Krasnosel'skil, Fixed points of cone-compressing or cone-extending operators, Soviet Mathematics. Doklady, 1(1960), 1285-1288.

[32] M.K. Kwong, On Krasnosel'skiน's cone fixed point theorem, Fixed Point Theory and Appl., 2008 (2008): 164537.

[33] K. Lan, Multiple positive solutions of hammerstein integral equations with singularities, Differ. Equ. Dyn. Syst., 8(2000), 175-195 
[34] K. Lan, Eigenvalues of semi-positone hammerstein integral equations and applications to boundary value problems, Nonlinear Anal., 71(2009), no. 12, 5979-5993.

[35] Q. Li, F. Cong, D. Jiang, Multiplicity of positive solutions to second order Neumann boundary value problems with impulse actions, Appl. Math. Comput., 206(2008), no. 2, 810-817.

[36] R. Ma, Nonlinear periodic boundary value problems with sign-changing green's function, Nonlinear Anal., 74(2011), no. 5, 1714-1720.

[37] I.-R. Petre, A. Petruşel, Krasnosel'skiu's theorem in generalized banach spaces and application, Electro. J. Qual. Theory Differ. Equ., 2012(2012), no. 85, 1-20.

[38] J.-P. Sun, W.-T. Li, Multiple positive solutions to second-order Neumann boundary value problems, Appl. Math. Comput., 146(2003), no. 1, 187-194.

[39] J.-P. Sun, W.-T. Li, S.S. Cheng, Three positive solutions for second-order Neumann boundary value problems, Applied Mathematics Letters, 17(2004), no. 9, 1079-1084.

[40] Y. Sun, Y.J. Cho, D. O'Regan, Positive solutions for singular second order neumann boundary value problems via a cone fixed point theorem, Appl. Math. Comput., 210(2009), no. 1, 80-86.

[41] F. Wang, Y. Cui, F. Zhang, A singular nonlinear second-order Neumann boundary value problem with positive solutions, Thai J. Math., 7 (2012), no. 2, 243-257.

[42] F. Wang, F. Zhang, An extension of fixed point theorems concerning cone expansion and compression and its application, Comm. Korean Math. Society, 24(2009), no. 2, 281-290.

[43] F. Wang, F. Zhang, Existence of positive solutions of neumann boundary value problem via a cone compression-expansion fixed point theorem of functional type, J. Appl. Math. Comput., 35(2011), no. 1-2, 341-349.

[44] J. Webb, Uniqueness of the principal eigenvalue in nonlocal boundary value problems, Discrete Contin. Dyn. Syst. Ser. S, 1(2008), no. 1, 177-186.

[45] J. Webb, A class of positive linear operators and applications to nonlinear boundary value problems, Topol. Methods Nonlinear Anal., 39(2012), no. 2, 221-242.

[46] J. Webb, G. Infante, Positive solutions of nonlocal boundary value problems, a unified approach, J. Lond. Math. Soc., 74(2006), no. 3, 673-693.

[47] J. Webb, G. Infante, Non-local boundary value problems of arbitrary order, J. Lond. Math. Soc., 79(2009), no. 1, 238-258.

[48] J. Webb, G. Infante, Semi-positone nonlocal boundary value problems of arbitrary order, Comm. Pure and Applied Analysis, 9(2009), no. 2, 563-581.

[49] J. Webb, G. Infante, D. Franco, Positive solutions of nonlinear fourth-order boundary-value problems with local and non-local boundary conditions, Proceedings of the Royal Society of Edinburgh, Section A Mathematics, 138(2008), no. 2, 427-446.

[50] J. Webb, K. Lan, Eigenvalue criteria for existence of multiple positive solutions of nonlinear boundary value problems of local and nonlocal type, Topol. Methods Nonlinear Anal., 27(2006), 91-115.

[51] J. Webb, M. Zima, Multiple positive solutions of resonant and non-resonant nonlocal boundary value problems, Nonlinear Anal., 71(2009), no. 3, 1369-1378.

[52] S. Zhong, Y. An, Existence of positive solutions to periodic boundary value problems with signchanging green's function, Boundary Value Problems, 2011(2011), no. 1, 1-6.

Received: January 27, 2016; Accepted: June 7, 2016. 
